\title{
Good expert knowledge, small scope
}

\author{
Horst Mayer ${ }^{\mathrm{a}, \mathrm{b}, \mathrm{c}, *}$

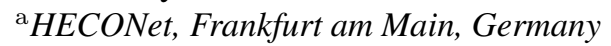 \\ ${ }^{\mathrm{b}}$ Stress Research, University Clinic Heidelberg, Heidelberg, Germany \\ ${ }^{\mathrm{c}}$ The ICOH subcommittee 'Functional Aspects of Vision at Work'
}

\begin{abstract}
.
BACKGROUND: During many years of occupational stress research, mostly within the German governmental program for "Humanization of Work Life", remarkable deficits concerning visual work were seen, the most striking being the lack of cooperation between the different experts.

OBJECTIVE: With regard to this article hard arguments and ideas for solutions had to be found.

METHODS/PARTICIPANTS: A pilot study in 21 enterprises was realized (1602 employees with different visual work tasks). A test set of screening parameters (visual acuity, refraction, phoria, binocular cooperation and efficiency, accommodation range and color vision) were measured. The glasses and/or contact lenses worn were registered and the visual tasks analyzed. In work at visual display units (VDU) the eye movements were recorded and standardized questionnaires were given (health, stress, visual work situation). Because of the heterogeneity of the sample only simple statistics were applied: in groups of different visual work the complaints, symptoms, hassles and uplifts were clustered (SAS software) and correlated with the results of the visual tests. Later a special project in 8 companies (676 employees) was carried out. The results were published in [14].

RESULTS: Discomfort and asthenopic symptoms could be seen as an interaction of the combination of tasks and working conditions with the clusters of individual functionalisms, frequently originating in postural compromises. Mainly three causes for stress could be identified: 1 . demands inadequate with regard to intensity, resolution, amount and/or time structure; 2 . prevention of elementary perceptive needs; 3 . entire use of partial capacities of the visual organ. Symptoms also were correlated with heteronomy. Other findings: influence of adaptation/accommodation ratio, the distracting role of attractors, especially in multitasking jobs; influence of high luminance differences. Dry eyes were very common, they could be attributed to a high screen position, low light, monotonous tasks and office climate. For some parameters a diurnal rhythm could be identified. Nowhere special programs for ageing employees were found: the right glasses; retinal problems and signs of destabilization of vision.

CONCLUSIONS: In all enterprises, the ergophthalmological and visual ergonomic knowledge of the occupational physicians was poor, visual ergonomists were not available and there was only very poor cooperation with ophthalmologists and optometrists, the first of whom additionally had not much knowledge of modern work.
\end{abstract}

Keywords: Ageing workforce, cooperation between experts and enterprises, efficiency of expert work on-site, environmental factors, ergophthalmology, visual ergonomics

\section{Preface}

In 1974 the German Ministry of Science and Technology and the Ministry of Labor and Social Af-

\footnotetext{
* Corresponding author: Horst Mayer, Östra Vadje 29, S-68593 Torsby, Sweden. Tel.: +46 560 42237; Mobile: +46 73 0510697; E-mail: M@yer.se; horst.mayer@eyes-at-work.de.
}

fairs started a more than three decades lasting program on "humanization of working life". As a late contribution the Section of Stress Research and Experimental Psychosomatics of the Department of Internal Medicine in cooperation with the Department of Orthoptics and Pleoptics of the Eye Clinic (both Ruprecht Karls Universität Heidelberg) carried out a project on visual work, which showed more deficits 
than successes. In a second step the initial field study in 21 enterprises was accomplished by a more detailed study in 8 enterprises. The results showed that despite some global progress in ergophthalmological knowledge the results very rarely reached the employees, and interviews with experts showed that in most cases their ideas were blocked because of the absence of result-centered cooperation. But in the enterprises of research the general ergophthalmological and visual ergonomics knowledge of the occupational physicians was poor, visual ergonomists were not available and there was only very poor cooperation with experts outside the enterprise like ophthalmologists and optometrists, the first of whom additionally had not much knowledge of modern work. Thus, research on many questions that arose from the analyses should be stimulated but the most prominent conclusion is the call for interdisciplinary cooperation in the enterprises.

\section{The significance of vision for the evolution of homo sapiens}

In the phylogenesis of man, far vision was most important. It guaranteed the orientation in time and space and the fast comparison of the inner and the outer world, predominantly to empower our command center, the limbic system. We must always keep in mind that our inner picture of the world is produced by our brain, not by the eyes [1]. Additionally, the peripheral retina needed the fastest image processing to detect lateral risks in the dark.

Within one single generation, the world population has mutated to an information processing and knowledge society where near vision is a sine qua non. Due to the globalization of production and communication technology this process is no longer limited to the industrialized parts of the planet.

Whenever phylogenetic development of vision is discussed, another aspect - mostly forgotten or at least unconsidered - comes to the fore, which recently gained some significance: In the early 1990's a type of photosensitive retinal cells, together with ganglion cells, both unknown until then, was discovered [2]. The function of these photosensors is not image-forming and completely different from the ones providing pattern vision: delivering a stable signal of ambient light intensity to different parts of the brain, predominantly via the retinohypothalamic tract to the suprachiasmatic nucleus in the hypothalamus. Another connection is with the center of pupillary control, the pretectal nu- cleus of the olive, the function of which is not only the regulation of pupil size. Their third important role is direct control of the melatonin production in the pineal gland and thus synchronizing our circadian rhythm. Taking these results into consideration we must not limit our reflections on the eyes to vision, they represent our central organ both for control of and orientation in space and time. What these findings mean for visual work still cannot be overseen; the first consequence must be that clear limits for rationalization of "salaried vision" are put forward. And it must always be kept in mind that our will has only limited access to our sensory functions.

\section{Visual labor: Use or abuse of the organ of seeing in a changing world of work?}

Currently the proportion of highly demanding visual tasks at work in close distances is still increasing, computers dominate the working world. Critical factors in this connection are among others, sustained accommodation, binocular functions and ocular surface alterations [3,4]. Mismatch of biological requirements and working conditions at visual work are responsible for visual (incl. asthenopic) complaints as well as pain syndromes of head, shoulders, arms and trunk (postural constraints) and a reduced work performance. The optimal fit of visual tasks to the needs of man therefore has to be considered not only as a problem of health, safety control and quality of life but as an important economic factor.

From year to year, working life makes greater demands on vision, not only in consequence of (partial) automation and technological "progress" in handling and assembling, but likewise due to the information technology's steady penetration of all levels of economy. Indisputably today the computer dominates the working world. In most cases it represents the only interface and communication means between the employee and the production or service world exclusively, occasionally even the only link to the employing enterprise. According to the latest surveys of the European Foundation for Living and Working Conditions $[5,6]$ in Europe, almost $50 \%$ of the employees between 40 and 54 and still $40 \%$ of the group $55+$ (the "presbyopic age") are performing "computer work"). The figures of the female working population are even higher. These figures seem to be underestimated because there is a large grey zone of part time employment, informal and homework. On the other side even at other (even more 
"classical") workplaces computers are integrated and screens are part of the man-machine-interface. In surveys they often are not listed. Additionally we have to regard that we must not limit our interest and responsibility to work with visual display screens. There are still quite a few visual work tasks without computers and during the years passed they have gone through considerable processes of rationalization by automation, which often results in condensation and intensification of tasks. Occasionally the visual ones are the only residual elements of human work in the manufacturing process (like continuous charging or output quality control of automated production lines). Likewise, craftsmen and women (and often children) in many countries often perform near work under indescribably poor conditions (like assembling jewelry or sewing clothes in dark corners of indoor markets).

Partly due to a lack or homogeneity in recording and documentation in the different countries, it is difficult to assess the real amount of health effects. According to Europe's Working Conditions Surveys mentioned above, up to $47 \%$ of the employees suffer from backache and up to $35 \%$ from headache. Furthermore, prevalence of the top-two eye symptoms in public buildings is about $30 \%[7,8]$. These data agree with previous findings $[9,10]$. So it can be estimated that in Europe more than 60.000 .000 persons suffer from problems originating from visual maladjustment, the management of which, according to the European legislation, is the task of industry, commerce and science (inter alia [11]). The current trend is upward, especially because of the ageing workforce. Interesting and in accordance with our own experience is the remark in [12], that the majority of the persons responsible for working conditions in the European enterprises still do not know about their duties and how to take appropriate action.

Nevertheless, the dictate and the economical power of the big software and hardware companies worldwide do not permit broader discussions of the ergonomic implications, not unlike the situation in the area of memory research, where the term "digital dementia" was created describing a phenomenon of poor memory and deterioration of cognitive abilities in teenagers attributed to using technology instead of the brain [13]. This is strengthened by the rapid and widespread dissemination of the computers and the compulsion to acquire the newest updates, in order to be able to hold one's own in the competition of the community of users. Fashionable trends and compulsions originating in the design of the global networks and server applications of the enterprises are supervening.

Software solutions are showing an increasing complexity - more and more coded "information" on the screen, a higher density by using more colors and smaller fonts etc., resulting in more difficulties for ageing employees - and centralization, which implicates a growing importance of the well-known problems of contrast, glare, color discrimination, etc.. But it is not only the complexity of the contents and the structure, but also the changing structure of the working time which altogether lead to sensitizing - in the sense of the "need for" working spectacles or medical interventions when working at the VDU - and adverse effects. In a couple of ergophthalmological field projects [14] it was found that managers and other people responsible for the working conditions were not aware of the fact that working spectacles, important as they are, can only partly solve the visual problems of ageing persons.

\section{The roles of the relevant experts in industry; reality and possible levels of influence and the needed rearrangement of tasks}

The medical eye experts are the ophthalmologists, but in their discipline and likewise in general occupational medicine and hygiene not many findings of ergophthalmology - the medical discipline with responsibility for vision at work -, if available at all, still are acknowledged appropriately. Though this is of significance for health, safety and well-being on one side and the preservation and improvement of the standards of work in production, service, administration, research and development, etc. on the other side, it is an indicator for the different time structure of the processes in the world of work and of the supporting services and the scientific background work respectively.

As mentioned above, presently the interest of the medical experts in visual labor, the ergophthalmologists, is mainly limited to work with visual display units (VDUs). In most industrialized nations the interest is reduced to the "right" spectacles and only occasionally to demands for "ergonomical" lay-outs of individual computer workplaces, which generally are spelled out as adjustments of chair and screen and, to a limited extent, lighting. Occupational physicians selfcritically have to admit that their activities concerning visual labor are often limited to so-called screening tests, which for the most part are reduced to an examination of the visual acuity, whilst binocular co- 
ordination, fusion, accommodation range and dynamics (velocity, dependence on adaptation, contrast distribution and fusion) and field of vision are left out. Furthermore, environmental and personal conditions are seldom integrated or even assessed. But even in the enterprises of the "western countries" we do not find much knowledge on the latter. Ergophthalmology (including visual ergonomics and environmental e.g. microclimatic conditions) very scarcely is one among many multidisciplinary topics in the education of occupational physicians.

The term "ergophthalmology" was created by the German ophthalmologist H. J. Merté 1966 at the XX. International Congress of Ophthalmology in Munich as the medical field covering "all interrelations between vision and work". Merté [15] lists the following areas of tasks:

- Harms to the organ of vision, caused by occupational activities (consequences of accidents, gradually developed work related or occupational diseases);

- Prevention of damages;

- Rehabilitation and reintegration into professional life and society, by retraining, e.g.;

- Assessment and evaluation of reductions in earning capacity, caused by loss of functional abilities and skills, as well as the assessment of fitness for professional use;

- Aids necessary for compensation of loss of vision;

- Defining the lay-out of a workplace for the best possible use of the powers of vision for achieving an optimal competitiveness;

- Defining the requests of the different kinds of job for visual functions;

- Aptitude tests;

- Prescriptions of visual aids;

- Careers guidance and the enforcement of visual tests laid down by legal directives.

The ICOH (International Commission on Occupational Health) Scientific Committee on 'Work and Vision' had defined ergophthalmology as the scientific umbrella that integrates analysis, evaluation and design of simple or complex working systems pertaining to the relationship between visual tasks and their depiction, working conditions, ocular and postural comfort, and visual performance [16]. Thus, reading Merté's list thoroughly we cannot oversee that a medical doctor in an enterprise dedicated to production or services usually is confronted with difficulties in being granted the reputation, that his demands with regard to technology and work organization - even if he is able to formulate them properly - will lead to efficient changes.

Ergophthalmology presently makes use of established knowledge derived from ophthalmology, ergonomics, industrial hygiene and occupational medicine, as well as from technology (physics, engineering, architecture, etc.), environmental sciences and social disciplines (psychology, sociology, etc.). Anyhow, "... the purposes of ergophthalmology are mainly the prevention and management of ocular discomfort and disease in order to obtain maximum efficiency and effectiveness of visual function in organized work" [16].

Considering the proportion of visual tasks in today's work, ergophthalmology has received very little attention or was not accepted by the professional community possibly because of its multifactorial nature and perceptions that interventions might be cost intensive. Therefore, in practice occupational physicians may consult such specialists like optometrists or ophthalmologists to help optimizing workplaces with (highly) demanding visual tasks. However, not everywhere on this planet such specialists may be aware of particular risk factors and requirements at work or methods essential for evaluation of reported complaints, of which some short-term effects may be absent away from the workplace. And when we inspect companies in different parts of the planet we do not find much change in the sense of an implementation of ergophthalmological knowledge yet. Some countries are better than others: In the sixties of the last century the Scandinavian countries began to appreciate the problem. They started new governmental research institutions and issued remarkable guidelines for visual work and its equipment. Special institutes were formed (e.g. Ivar Lies Synsklinik in Oslo) and occupational health institutes built up ergophthalmological labs (e.g. in Karolinska Universitetet in Stockholm Solna or Jorma Rantanens former institute in Helsinki).

\section{Consequences}

As a result of the above catalogue of objectives, modern ergophthalmology is confronted with the following key factors and tasks:

- Interdisciplinary effort involving different players in the enterprise, especially the urgently needed amalgamation of ergophthalmology and visual ergonomics, but also the encouragement of working groups within the enterprise, including technicians, occupational physicians and hygienists, workers' representatives, social workers and safety specialists focusing prevention. 
- Participation and cooperation of occupational physicians, visual ergonomists and hygienists with ophthalmological practitioners, environmentalists and general ergonomists for a better harmonization of the interface between man, environment and machine. Cooperation with opticians and optometrists, with family doctors, employer's liability insurance associations like the German Berufsgenossenschaften, health insurance agencies etc. for joint assessment of company surveys on the data of insured persons and case histories.

- Comprehensive approach:

* Information for employees on interrelations between visual tasks and stress as well as postural problems, sensitization to possibilities of influencing stress, training and help for self-help, counselling and training (how to use the available alternatives etc.).

* Evaluating risk of exposures to different agents (chemical, biological, physical) and environmental conditions (climate).

* Visual testing, recording of symptoms and signs.

* Analysis of work tasks: duration and characteristics of repetitive elements of visual tasks, saccades and pursuit movements needed, fixation processes, working posture etc..

* Determining other visual requirements and workplace prerequisites for effortless visual work.

* Adequate recognition of psychosocial factors (stress, organizational climate) and the central nervous processes of visual perception.

For practical reasons ergophthalmology firstly must not limit itself to the eyes but must take into consideration the whole complexity of visual performance including both the basodynamics and teleokinetics of posture facilitating near vision work, as well as the neuropsychology of perception. Recently brain research has found, that visual perception is the result of the work of mainly 4 brain centers whilst some dozen more are involved [17]. Secondly, the influence within the working environments will become much better if it will be mediated and arranged by visual ergonomists, because most of them are familiar with the technical and economic codes of the everyday communication in an enterprise. There are signs that the experts of the disciplines which form the basis of ergophthalmology slowly become aware of it's importance: The ophthalmologists E. Rozanova, P. Heilig and P. Godnić-Cvar in 2009 published a paper with the head- line "The eye - a neglected organ in environmental and occupational medicine" [18].

Thus it is the intention of this paper to help occupational physicians and hygienists as well as ergonomists worldwide to assert their influence both on visual working conditions and the relevant design and functions of production means and material. Ergophthalmology should also be regarded as an important tool in the strategic concepts of global programs concerning visual work and health, which presently is not at all the case. For instance, little attention in occupational medicine can be found with regard to environmental conditions relevant to the outer eyes (microclimate, e.g. indoor pollutants and formaldehyde) and other basic factors of both the inner and outer eyes physiology, even though they had been alleged as causative to a couple of problems [19].

Seeing usually takes place successfully without perceiving its complexity. Much more than muscle work, salaried vision is characterized by remarkable individual differences. Hardly two human beings have the same eyes, the differences mostly being in the form of norm variants at least of refraction or positional deviations, occasionally problems of binocular cooperation, but without medical significance. From the earliest infancy we train the cooperation of our eyes unconsciously. But this ensemble acting may be disrupted when, due to incessant monotonous near work, a constant systemic load causes muscular fatigue and/or waning attentiveness. Nevertheless a partial weakness of one or both eyes may be compensated by binocular cooperation.

The ophthalmologists' role is different, depending on the specific legal situation of the particular country. In Germany, for example, they are put in charge of work with VDUs in so far as the so-called supplementary examinations are their field of action. Nevertheless many of them have negligible understanding of the complex interrelations that are part of the fast dynamic and visually demanding processes of modern office work. It will be the future obligation of Occupational Medicine to start a sophisticated dialogue. This will help the ophthalmologist to be in the position to give recommendations of practical relevance at work. Nowadays, in most cases it is not at all sufficient to prescribe "VDU-spectacles". In contrast, in Australia and in Scandinavia the optometrist is the primary contact, no one is admitted to an ophthalmologist directly without an optometrist's referral, except when referred by a general practitioner.

Having in mind the redefinition of the roles of the relevant experts in industry, four decisive questions come to the fore [20]: 
- What can the company do to resolve the problem (e.g. regulation of the climatic or lighting conditions)?

- What can the employee do?

- Which "prosthetic aid" (e.g. spectacles) will support the workplace-specific role?

- What can the enterprise learn from this particular case?

Concentrating on the pragmatism of these questions we hope that a fruitful process of communication can be triggered. Furthermore we have to show to the enterprises the advantages they gain from this cooperation. The author is happy to have had the chance to cooperate some years ago with WHO's regional office for Europe, Copenhagen, in formulating GPHESSME (Good Practice in Health, Environment and Social Capital Management in Enterprises). Here some methods are described. In HECONet, the Healthy Companies Network, U. Adler has developed a sophisticated system for evaluation of health promotion in enterprises [21]. Although the consideration of ergophthalmological and visual ergonomic knowledge in practice is just as important as other occupational health research, this evaluation did not take place yet. However, both need to be benchmarked constantly and brought up to date in their field of action, which is the enterprise.

An additional goal of this paper is to stimulate the elaboration of models of the functional and sophisticated structure of visual labor including the stressstrain aspects. In order to achieve working environments that both maintain and are conducive to efficiency (good performance), an integral approach to vision, based upon established findings of physiology of work is required. Only a better comprehension of the complexity of vision can serve as a basis. In order to fulfill the necessities that arose from the new demands of visual labor, ergophthalmology still needs substantial scientific input and basic research like the examples listed below:

- The complexity and parallel fold of static and dynamic visual work;

- The chronological factors of the combination of fusion, accommodation and adaptation;

- The dependency of the threshold luminance for the recognition of symbols and characters on their size;

- The emergence and significance of the "intermediary focus" and the "dark focus" for effortless near work [22];
- The already well known disturbance of suppleness of focusing by sounds and noise, resulting in the motoric tendency to compensate these permanently [23];

- The interaction between senses, for example vision and hearing [24];

- The relation to emotions;

- The regulation of body position;

- Research on the application of the model of visual performance and its relationship with overall task performance in visual ergonomics.

In the future neuropsychology might play an important role for ergophthalmology: The role of mental/visual attractors, mental and emotional constriction by hindrance of visual control mechanisms of vitality, cerebral processes for capture of static screen contents (required eye movements etc.), the "tunnel-sight", visual needs, acceptance of visual tasks including their alternations and sequential connections and of software in its entirety, the role of internal images, etc.. Brain research has demonstrated that consciousness is discontinuous [25]. Little knowledge exists about the interactions of these so-called 'point processes' of consciousness, their cycles and spaces with visual input and visuomotor activity as a whole [26].

A number of (combined) factors that influence the outer eyes causality and symptomatology and their relative impact compared with the inner eyes symptomatology is not known and how they may interact. Likewise it concerns the development of tests for the above mentioned parameters and environmental conditions, resulting in output of practical relevance on the shop floor. A detailed discussion of the "Problems of the" outer eyes "in the Office Environment" was published recently [19].

An upcoming field of primary prevention concerns soft- and hardware in control centers, in banking, power plants and the chemical industry, in steel mills and air traffic control. Here the lack of standards, defined by neurophysiology of labor, is evident. Developmental engineers as well as buyers of equipment need to have unequivocal guidelines. One of the prominent reasons for this requirement is the fact that here ergonomics and environmental issues also have the aspect of safety in so far as the unambiguity of signals and information in critical and stressful situations is to the fore.

On the part of applied ophthalmological research we have reached a level of knowledge that allows us to understand roughly the immense complexity of processes making up the eyes' work. What is still missing is 
the participation of brain researchers. We find only islands of detailed knowledge (traffic and aerospace ophthalmology, e.g.), while broader and extensive application research is still needed. Experience has shown that bridges between these islands may create an abundance of practical experience. On a broad basis of empirical data occupational medicine needs to be in a position not only to influence work routines and workplaces, but, in close cooperation with ergonomists, also to have an influence on the production of software.

Another difficulty is due to the fact that quite a few means and even strategies for organizing and structuring visual work originate in the paradigms of muscle work and do not take into account the basics of sensory work. Visual information always is multifunctional. In the end we are not able to disintegrate and select the components desired without processing the other signals, as a result of which the whole individual participates in the respective process of performance. All our perceptions are accompanied by sentiments with consequences for our processes of (e.g. autonomic or postural) control and general vitality. Quite frequently, in ageing persons we find a disintegration of this holism of work by a (relative or absolute) increase in sensory information. So, systems- and process-ergonomics are to the fore.

To summarize the introductory remarks, it seems worthwhile to consider that the subject of ergophthalmology is one of the most complex areas of the psychobiology of humane functions. Neither the mostly monodisciplinary - knowledge of mechanical and even sensory functions of the eyes nor using a meta-terminology like the one from psychology of perception can explain the magnificent phenomena or strange difficulties of vision. What will have to be our future task is not to be discouraged and go on following a scientifically adequate holistic approach without neglecting the monodisciplinary details.

Are ergophthalmology and visual ergonomics really needed? Asking relevant colleagues, most answers and predictions were negative, even if many of them consented to their general importance. Nevertheless when we published a summary of our position paper on ,Functional Aspects“ in the $2008 \mathrm{ICOH}$ summer Newsletter [27], the link was activated more than 600 times!

In the majority of our discussions, one argument never was touched: the ageing workforce. Presently we are confronted with a dramatic change in agedistribution, not only in the industrialized countries. Whilst the amount of visually highly demanding work- places increases continuously, the average age of the workforce increases, too. Thus it is necessary to prioritize ergophthalmology/environmental conditions/visual ergonomics in the education of both the occupational physician and hygienist in order to ensure an efficient optimization of visual work conditions, which likewise fit individual needs and performance of visually mediated work. An understanding and orientation towards the special requirements of an ageing workforce and individuals with "normal" deficiencies will also facilitate improvement of working conditions for younger employees with still perfect vision. Ageing eyes are characterized by presbyopia, a narrow accommodation range, and gland dysfunctions. They need more light, but are more sensitive to glare. They need more frequent examinations to detect age-related cataracts, changes of the vitreous body, retinal and ocular surface alterations, degenerative macula processes (AMD) etc. Anyway it has to be realized that many of the ageing processes of eyes and brain have their beginning in the middle of the highly productive age. Taking the optimization of work for elder employees - not only visual work - into consideration therefore could become a model area of humanization of working life for all ages.

According to Mertés definition of ergophthalmology it represents a branch of the area of health management at work and is not only ophthalmology applied in the field of health risks arising from working conditions. Therefore, it seems appropriate to follow the definitions of the World Health Organization (WHO) with regard to health at work. In July 1997, WHO in Jakarta published its "Healthy Work Approach" [28,29], which specified in more concrete terms the "Global Strategy on Occupational Health for All" adopted by the General Assembly in 1996. The Healthy Companies Network (HECONet) [30] was the first practical implementation of this concept. In April 1997, at the $3^{\text {rd }}$ Meeting of WHO's Collaborating Centres in Occupational Health in Santafé de Bogotá, Colombia, HECONet was announced by WHO's Department of Occupational Health and in September the launch meeting took place in Heidelberg, Germany. In this program, four fundamental principles are considered as important:

- Health promotion;

- Occupational health and safety;

- Human resources management;

- Sustainable social and environmental development. 
In the area of health promotion first indicators of a paradigm change in the world of work are visible, which is only very gradually including ergophthalmology. This leaves customary deterministic thinking behind, extends to holistic approaches (systems, processes) and participation in striving for ergonomic objectives; in the medical regions of occupational sciences it comprises thinking in terms of pathological processes up to salutogenesis [31] and physiology that is concerned with work performance.

In order to bring about change, the importance of five key elements is emphasized:

- Creating supportive environments;

- Empowerment of individuals and groups of people;

- Active participation of all concerned parties;

- Combination of a variety of different approaches;

- Intersectoral cooperation;

After a promising start, it had to be admitted that a program like HECONet needed an enormous financial background, which was not available. So HECONet

\begin{tabular}{|c|c|}
\hline Key elements: & $\begin{array}{l}\text { Tasks for ergophthalmology and visual } \\
\text { ergonomics: }\end{array}$ \\
\hline $\begin{array}{l}\text { Creating } \\
\text { supportive } \\
\text { environments }\end{array}$ & $\begin{array}{l}\text { Definition of individual visual needs and pre } \\
\text { requisites for effort- less visual work: qual- } \\
\text { ity and quantity of illumination, contrast, } \\
\text { colours, locations of the visual targets and their } \\
\text { topochronology etc.; implications for work or- } \\
\text { ganization: time structure of tasks, degrees of } \\
\text { freedom. }\end{array}$ \\
\hline $\begin{array}{l}\text { Empowerment } \\
\text { of individuals } \\
\text { and groups of } \\
\text { people }\end{array}$ & $\begin{array}{l}\text { Information of employees on interrelations be- } \\
\text { tween visual tasks and stress as well as postural } \\
\text { problems, sensitisation to the possibility of in- } \\
\text { fluencing stress (adjustment of monitors, light- } \\
\text { ing and workplace design), counselling with re- } \\
\text { gard to visual aids and training (how to use the } \\
\text { disposable alternatives etc.) }\end{array}$ \\
\hline $\begin{array}{l}\text { Active partici- } \\
\text { pation of all } \\
\text { concerned } \\
\text { parties }\end{array}$ & $\begin{array}{l}\text { Encouragement of the working groups within } \\
\text { enterprise, including technicians, occupa- } \\
\text { tional physicians, social workers and safety } \\
\text { specialists. }\end{array}$ \\
\hline $\begin{array}{l}\text { Combination } \\
\text { of different } \\
\text { intersectoral } \\
\text { coope }\end{array}$ & $\begin{array}{l}\text { Cooperation with occupational phasicians for } \\
\text { better harmonization of the variety of interface } \\
\text { between man and approaches machine: evalua- } \\
\text { tion of exposures to different agents (chemical, } \\
\text { biological, physical), in-depth and specialin- } \\
\text { vestigations (binocularity, contrast sensitivity, } \\
\text { accom- modation range and speed etc.), cooper- } \\
\text { ation with opticians and optometrists, recording } \\
\text { of symptoms, analysis of work tasks, saccades, } \\
\text { pursuit movements and fixation processes, etc. } \\
\text { with family doctors, nonhospital ophthalmolo- } \\
\text { gists, employer's liability ration insurance asso- } \\
\text { ciations, health insurance agencies etc. for joint } \\
\text { assessment of company surveys on the data of } \\
\text { insured persons and case histories. }\end{array}$ \\
\hline
\end{tabular}

had to concentrate on smaller areas of activities. One of them was the ooccupational psychophysiology of vision (see the epilogue). Projecting these key elements onto the screens of ergophthalmology and visual ergonomics, the following list seems reasonable:

A clear compulsory allocation of responsibilities/ tasks depends on several particular characteristics of the functional setting.

Despite all efforts until now, we see a lack of efficiency and effectiveness in an endeavor for a better world of visual work. There are many reasons, some of them already mentioned. In the enterprises we see a lot of prejudice and fear of a possible avalanche of costs, combined with an underestimation of the complexity of vision. There is also the fact that the experts (occupational physicians, ergonomists) in most countries are on the payroll of the company, which can cause quite a few problems. Another one lies in the fact that ergophthalmologists generally are eye specialists, and nobody is willing to pay for the enormous time they need for competent functional examinations and consultations.

\section{Outlook on topics: Outer eye - inner eye - brain - what else?}

Within HECONet we have therefore agreed on ergophthalmological priorities that may serve as guidelines for the reorganisation of tasks. They consist of the following five survey and counselling areas:

1. Application of research: Provision of information and counselling with regard to definitive ergophthalmological knowledge. Here we are still looking for partners all over the world who are prepared to act as experts in this network.

2. Basic research: This rather small sector comprises the areas of our own competence: microlevel investigations on the manner of coping with visual tasks by means of measuring goggles, the time dimensions of everyday visual work, visual work performance of older employees and the connection between visual problems and stress. Another topic - almost unregarded - is the function of peripheral (perifoveal) vision for smoothing the visual processes [32].

3. Applied research: In companies which are explicitly aware of visual work problems, the integration and implementation of external or internal contributions to solutions and the conditions achieved are established by means of process evaluation. The information obtained is used for further development of the field. 
Table 1

Future needs for further activities and investigations

\begin{tabular}{|c|c|}
\hline Some topics from the outer eye: & $\begin{array}{l}\text { - Indoor environmental risk factors: temperature, humidity, draft, chemical and microbiological } \\
\text { burden, surface contamination. } \\
\text { - Outdoor environmental risk factors: pollution etc. } \\
\text { - The "dry eye" syndrome pathophysiology. } \\
\text { - Gaze and posture. } \\
\text { - Glasses and contact lenses. } \\
\text { - Use of medication with diuretic properties. } \\
\text { - Personal care products (eye drops, cosmetics). } \\
\text { - Hygienic habits. } \\
\text { - Influence of geographical location (e.g. altitude). }\end{array}$ \\
\hline Topics from the inner eye: & $\begin{array}{l}\text { - Mismatch of requirements and individual resources. } \\
\text { - Optometric measurements, evaluation of visual performance incl. binocularity, heterophoria and } \\
\text { heterotropia. } \\
\text { - Visual aids: Theoretical understanding of glasses, contact lenses, refractive surgery; working } \\
\text { spectacles and relevant legislation. } \\
\text { - Diurnal rhythm and transient myopia. } \\
\text { - Status after lens implantation and after refractive surgery. }\end{array}$ \\
\hline Others: & $\begin{array}{l}\text { - "Classical" occupational medicine of the eyes: risks and work related illnesses. } \\
\text { - Possibly: treatment of health problems. } \\
\text { - Examples from the shop floor: Posture and vision in assembling (jewelry, sewing); multiple } \\
\text { screen work under time pressure in TV production; the role of glare in earthbound, aerospace } \\
\text { and sea traffic; visual work of ophthalmic surgeons and dentists, etc.. } \\
\text { - Interrelations of vision and stress. } \\
\text { - Different mismatches - different coping strategies and (e.g. postural) compensations. } \\
\text { - Structure of screen contents and its saccadic implications. } \\
\text { - Adjustment of the workplace climatic and ergonomic conditions. } \\
\text { - Lighting and type of near work. }\end{array}$ \\
\hline Multiple testing & $\begin{array}{l}\text { - Validity and reliability of tests and parameters. } \\
\text { - Evaluation of age, gender, dynamics of complaints, use of contact lenses, medication, etc. } \\
\text { - Evaluation of the microclimatic and ergonomic conditions. } \\
\text { - Evaluation and adjustment of the lighting conditions and the concomitant sensory situation. } \\
\text { Optometric measurements and adequate intervention. }\end{array}$ \\
\hline $\begin{array}{l}\text { Encouragement of problem-oriented } \\
\text { and pertinent cooperation of ergoph- } \\
\text { thalmologists and visual ergonomists } \\
\text { - both generally and case-centered } \\
\text { with }\end{array}$ & $\begin{array}{l}\text { - General ophthalmologists, } \\
\text { - Optometrists, } \\
\text { - Indoor air scientists, } \\
\text { - Safety engineers, } \\
\text { - Software specialists and } \\
\text { - The procuring department of the enterprise. }\end{array}$ \\
\hline
\end{tabular}

4. Ergophthalmological counselling and support of persons with eye problems in working life: These are above all progressive diseases with loss of visual performance and episodically occurring inflammatory eye diseases with a marked interaction with work (e.g. uveitis), but also ,minor“ problems like dry eyes and, not to forget, the visual problems of healthy, but ageing employees.

5. Basic documentation: Regular surveys contain some questions with regard to the significance of eye problems at work and the importance of visual orientation in the context of activities to promote health in the company. These activities should be presented as statistics and in addition, spontaneously reported interests or activities should be recorded. This may also serve as a data pool for controlling the - if calculated prop- erly - in most cases positive costs and benefits of health promotion by extended profitability analysis, e.g. [21].

Trying to bring the two levels - general health management at work and ergophthalmology/visual ergonomics - together, it may be reasonable to cluster the problems into three main categories:

- Mechanisms predominantly focusing the "Outer Eye",

- Mismatch of concrete demands on and possibilities of the "inner eye" (visual targets: size, color, contrast; accommodation, binocularity etc.);

- Mismatch of demands of visual tasks and neuropsychic physiology.

With regard to this splitting up some topics that require further investigations and activities, regardless 
whether they originate in the fields of ergophthalmology or visual ergonomics, according to general beliefs. They are given in Table 1.

\section{Closing remarks}

Two years ago, a small group of Swedish, Danish, German and Austrian scientists began collating material for something like a "Primer of Ergophthalmology", because nothing similar could be found on the market. Each member should be allowed to put in his or her opinion and findings. The focal interest always was the broad and direct application of existing knowledge, which more or less still is an utopia. Some of the group favoured the classical strategy, writing a book or a series of articles, some preferred an e-book freely accessible. Recently serviceable contacts with visual ergonomists came about, which led to reflexions about an expansion of the concept, but keeping the idea of free access for everybody. And what else could serve here but Internet? So, it was decided in HECONet to build up an interactive system the starting version of which will consist of all the material already gathered for "the primer" parked on a special server under "eyes-at-work". Then everybody interested will have access and the opportunity to send supplementing material, the implementation of which will have to pass a process of "formal-methodical" evaluation by an open group of experts. Thus, chances are that a knowledgepool will develop, that on the one side will have validity and on the other side can be applied immediately.

Whatever the future will bring to the field of vision at work, we should always be aware of this:

We cannot optimise the visual interface without bearing in mind that we talk about one of the focal points of human consciousness and the most important informational channel in the field of quality of life.

\section{References}

[1] Hoffmann DD (2001), Visuelle Intelligenz. Wie die Welt im Kopf entsteht. (Visual intelligence. How the world come into being in our head) Klett-Cotta, Stuttgart.

[2] Foster RG, Provencio I, Hudson D, Fiske S, DeGrip W, Menaker $M$ (1991) Circadian photoreception in the retinally degenerate mouse. J Comp Physiol 169: 39-50.

[3] Thomson, W.D. (2001), Eye problems and visual display terminals-the facts and the fallacies. Ophthal Physiol Opt 18 : 111-119.
[4] Wolkoff P (2008), "Healthy" eye in office-like environments. Environ Int 34(8): 1204-1214.

[5] European Foundation for the Improvement of Living and Working Conditions (2007), Fourth European Working Conditions Survey. Dublin.

[6] European Foundation for the Improvement of Living and Working Conditions (2010), Changes over time - First findings from the fifth European Working Conditions Survey Dublin.

[7] Bluyssen, P.M., de Oliveira Fernandes, E., Groes, L., Clausen, G., Fanger, P.O., Valbjørn, O., Bernhard, C.A. and Roulet, C.A. (1996), European indoor air quality audit project in 56 office buildings. Indoor Air $\underline{6}$ : 221-238.

[8] Brightman HS, Milton DK, Wypij D, Burge HA, Spengler JD (2008), Evaluated building-related symptoms using the US EPA BASE study results. Indoor Air 18: 335-345.

[9] Mayer H, Kraus-Mackiw E (1998), Stress by Inadequate Visual Work - Interrelations between Vision and Sitting Posture. Global Ergonomic Conference, Cape Town, Republic of South Africa, 9-11 September.

[10] Mayer H, Kraus-Mackiw E (1999), The Role of Ergophthalmology in the Healthy Companies Network (HECONet). Ergophthalmology session, XII Congress of the European Society of Ophthalmology (SOE). Stockholm, Sweden, 27 Juni 1 Juli.

[11] EEC, European Directive 90/270/EEC on the "Minimum Health and Safety Requirements for work with Visual Display Screen equipment".

[12] TNS Infratest Sozialforschung GmbH (2007), Evaluation der Bildschirmrichtlinie 90/270 EWG. (Evaluation of the European Council Directive 90/270/EEC for work with display screen equipment). (Im Auftrag des deutschen Bundesministeriums für Arbeit und Soziales) München, Germany.

[13] Spitzer $M$ (2012), Digitale Demenz. (Digital Dementia). Droehmer Verlag, München.

[14] Mayer H, Kraus-Mackiw E (1999), Entwicklung von Methoden zur Identifikation visueller Ursachen arbeitsbedingter Gesundheitsrisiken und hierauf bezogener Präventionsstrategien im betrieblichen Gesundheitsschutz. (Development of Methods for Identifying Visual Causes of Work-related Health Risks and Strategies for Their Prevention). Forschungsprojekt, gefördert durch das Bundesministerium für Bildung, Wissenschaft, Forschung und Technologie BMBF (FKZ: 01 HP 594/9); Schlussbericht. Heidelberg, Berlin, Juli 1999

[15] Merté HJ (1978), Die Bedeutung der Ergophthalmologie. (The Importance of Ergo-Ophthalmology). Arbeitsmedizin, Sozialmedizin, Präventivmedizin $\underline{13}$ (5): 89-93.

[16] Piccoli B (on behalf of the ICOH Scientific Committee 'Work and Vision') (2003), A critical appraisal of current knowledge and future directions of ergophthalmology: consensus document of the ICOH Committee on 'Work and Vision'. Ergonomics $\underline{46}$, \# 4: 384-406.

[17] Felleman DJ, Van Essen DC (1991), Distributed hierarchical processing in the primate cerebral cortex. Cerebral Cortex $\underline{1}$ : $1-47$.

[18] Rozanova E, Heilig P, Godni-Cvar J (2009), The eye - a neglected organ in environmental and occupational medicine: an overview of known environmental and occupational nontraumatic effects on the eyes. Arh Hig Rada Toksikol 60: 205215 .

[19] Wolkoff P, Kärcher T, Mayer H (2012), Problems of the "Outer Eyes" in the Office Environment. An Ergophthalmologic Ap- 
proach. Journal of Occupational and Environmental Medicine (JOEM) 54 (5): 621-631.

[20] Mayer H, Breitstadt $R$, Hahn H, Horgen $G$, Kraus-Mackiw E, Müller U, Rosner M, Seiffert B, Wolkoff P (2009), Curriculum Ergophthalmology. 29 $9^{\text {th }}$ ICOH International Congress on Occupational Health. Cape Town, South Africa, 23.-28. March 2009.

[21] Adler $U$ (2000), Costs and Benefits in Occupational Health and Safety. Ifo discussion paper \#70, Ifo Institute for Economic Research, München.

[22] Owens DA, Andre JT, Owens RL (2000), Predicting accommodative performance in difficult conditions: A behavioral analysis of normal variations of accommodation. In: Franzén $O$, Richter H, Stark L: Accommodation and Vergence Mechanisms in the Visual System, pp. 273-284. Birkhäuser Verlag,

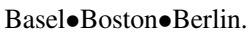

[23] Jansen $G$ (1962), Beeinflussung der Konvergenztrias durch Geräusche. (Influences of Sound on the, Trias of Convergence'). Excerpta Med. Intern. Congr. \# 48, Leiden.

[24] Zajonc A (1993), Catching the Light: The Entwined History of Light and Mind. Bantam Books, New York.

[25] Bodovitz S (2008), Consciousness disintegrates without conscious vectors. Med Hypotheses 70(1): 8-11.

[26] Singer $W$ (2002), Der Beobachter im Gehirn (the spectator in the brain) Essays zur Hirnforschung Suhrkamp, Frankfurt ISBN 3518291718.

[27] Mayer $H$ (on behalf of the ICOH Scientific Subcommittee 'Functional Aspects of Vision at Work') (2008), Functional Aspects of Vision at Work ICOH Newsletter Vol.6 \#3.

[28] WHO (1995), Global Strategy on Occupational Health for All. The Way to Health at Work. WHO document OCH/95.1 Geneva: WHO.

[29] WHO (1997), WHO's global Healthy Work Approach. A strategy for the development of a comprehensive approach toward the promotion of health of all working populations. WHO document HPR/HEP/97.2. Geneva: WHO.

[30] Rodriguez de Villamil J, Mikheev M, Mayer H (2000), Healthy Working Environment: The Healthy Companies Network (HECONet). Programme Description. HECONet Document HC 00-02 E.

[31] Antonovsky, A (1979), Health, Stress and Coping Jossey-Bass Publishers, San Francisco etc.

[32] Springer SP, Deutsch G (1998), Left Brain - Right Brain. Perspectives from Cognitive Neuroscience. $5^{\text {th }}$ edition, Freeman ISBN 0-7167-3110-X.

\section{Annex: Glossary}

\section{Accommodation}

The process by which the eye increases optical power to provide the best definition possible for a certain distance by means of the focusing ability of the lenses. There are two mechanisms: changing the lenses' tension ("outer accommodation") and restacking and changing the form of its fibers ("inner accommodation"). The difference between the refractive power of the lenses at the nearest point possible (in diopters) and the one at the farthest point is called accommodation range. It shows a negative correlation with age.
AMD (age-related macular degeneration)

Age related macular degeneration is a medical condition which usually affects older adults that results in a loss of vision in the center of the visual field (the macula) because of damage to the retina. It occurs in "dry" and "wet" forms. It is a major cause of visual impairment in older adults ( $>50$ years). Macular degeneration can make it difficult or impossible to read or recognize faces, although enough peripheral vision remains to allow other activities of daily life.

Asthenopia

Eyestrain; subjective symptoms of ocular fatigue, discomfort, Lacrimation, and headaches from use of the eyes.

Basodynamics

Specific neuromuscular innervation pattern aiming at enabling/supporting a concrete dynamic (teleokinetic) action.

Binocularity

Cooperation of the two eyes.

Circadian rhythm

Biologic rhythms with a cycle of about 24 hours.

Dry Eye Disease Keratoconjunctivitis sicca (KCS), also called keratitis sicca, sicca syndrome, http:// en.wikipedia.org/wiki/Dry_eye_disease-cite_note -eMedicine-1-0 xerophthalmia, dry eye syndrome (DES), http://en.wikipedia.org/wiki/Dry_eye_ disease - cite_note-eMedicine-1-0 or simply dry eyes, is an eye disease caused by decreased tear production or increased tear film evaporation commonly found in humans and some animals.

Ergophthalmology

The segment of ophthalmology dealing with interrelations between vision and work: prevention and treatment of work-related diseases and injuries, rehabilitation, defining the requirements for unimpeded visual work, including its temporal dynamics; aptitude tests.

Heterophoria

A tendency for deviation of the eyes from parallelism, prevented by binocular vision. (S)

Heterotropia

Strabismus (from Greek $\sigma \tau \rho \alpha \beta \iota \sigma \mu o ́$ from $\sigma \tau \rho \alpha$ $\beta i \zeta \varepsilon \iota \nu$ "to squint") is a condition in which the eyes are not properly aligned with each other. It typically involves a lack of coordination between the extraocular muscles that prevents bringing the gaze of each eye to the same point in space and preventing proper binocular vision, which may adversely affect depth perception. Strabismus can 
be either a disorder of the brain in coordinating the eyes, or of one or more of the relevant muscles' power or direction of motion. (W) Very frequently we find retinal (foveolar) disturbances as a primary cause.

Hypothalamus

Central part of brain (the limbic system; under cerebrum) involved in autonomous nervous and endocrine functions.

Limbic system

A set of central brain structures responsible for emotions, learning, some memory functions and motivation.

Melanopsin

Melanopsin is a photopigment found in specialized photosensitive ganglion cells of the retina that are involved in the regulation of circadian rhythms, pupillary light reflex, and other nonvisual responses to light.

Melatonin

Neurohormone steering the circadian rhythm, produced by the pineal gland.

Ontogenesis

The development of an individual.

Phylogenesis

The development of a species in evolution.

Pineal gland

Small endocrine gland under the center of the brain, producing melatonin, a serotonin derivate.
Presbyopia

The physiologic loss of accommodation in the eyes in advancing age, said to begin when the near point has receded beyond $22 \mathrm{~cm}$.

Retinohypothalamic tract

The tract which connects the ipRGC (intrinsic photosensitive retinal ganglion cells) directly (only one synapse!) to the suprachiasmatic nuclei of the hypothalamus.

Salutogenesis

The opposite of pathogenesis, defining factors promoting health and quality of life. Particularly with regard to working life Aaron Antonovsky [1] found coherence of work characteristics (comprehensibility, manageability and meaningfulness, e.g.) to be prominent factors.

Sine qua non

Imperative prerequisite. From Latin: conditio sine qua non.

Teleokinetics

Neuromuscular functional pattern bringing about a concrete dynamic performance.

Topochronology

Structural conditions with regard to space and time.

Vegetative nervous system

The vegetative or autonomic nervous system (ANS) is the part of the peripheral nervous system acting as a control system i.a. for visceral functions. 